\title{
Radical threats of spiritual security of the society
}

\author{
Jamal Kedeibaeva ${ }^{1, *}$, Damira Akmatova ${ }^{1}$, Karamat Belekova ${ }^{1}$, Kylychbek Kurbanbaev ${ }^{1}$, \\ Ainura Barynbaeva ${ }^{1}$ \\ ${ }^{1}$ Osh State University, Kyrgyzstan
}

\begin{abstract}
Each state and people has its own set of internal and external threats and, accordingly, its own specifics of ensuring national and spiritual security. Ensuring national security is associated primarily with the preservation and development of national identity, reflecting the traditions of the life of society, its culture and history. The degradation and then the disappearance of national (or ethnic) self-awareness means, in fact, the spiritual death of the people - the bearer of this self-awareness. Therefore, everything that threatens the destruction of national self-consciousness, fraught with the danger of its dissolution in the self-consciousness of other peoples, is a threat to the spiritual security of the people. Among the obvious internal premises that ensure the national and spiritual security of our country, we should name the unification of the people to solve national tasks of a spiritual and material order, the awareness of its representatives of their own interests and the manifestation of an organized will to protect them, optimized state institutions ready to ensure the protection of national interests, to guarantee stable and harmonious development of society, anticipating spiritual, cultural and scientific development, maintaining general stability in the state, establishing mutually beneficial business partnerships with all states of the world, but also taking into account a distant historical perspective, ensuring reliable protection of the sovereignty, integrity and security of your state.
\end{abstract}

\section{Introduction}

In modern conditions, the spiritual development of society is becoming one of the most important factors in ensuring its national security. Qualitative features of the spiritual world of the individual, social strata and groups determine the state of social relations in terms of their steadiness and stability, dynamics of development and reproduction. Social-andphilosophical analysis of the spiritual sphere as a factor of national security focuses on the consideration of universal meanings, essential features and characteristics, the depth of actualized phenomena of social life. The study of social evolution and the logic of social processes makes it possible to identify changes in the system of historical, spiritual, cultural and moral values and, accordingly, the dynamics of social development in situations of risks, challenges and threats.

The topic under study involves a deep examination of the phenomenon of spiritual risks and threats, as well as the factors of modern reality that generate such risks and threats. Thus,

\footnotetext{
*Corresponding author: kedeybaeva1976@mail.ru
} 
S.I. Artanovsky, E.I. Bashkirova, A.G. Zdravomyslova, N.I. Lapin, V.V. Lokosova, G.V. Osipov, A.O. Panfilova, V. Petrenko, A.V. Filippova, A. Efendieva and others has analyzed the crisis of social values in terms of the threats and risks generated by them for the spiritual state of society, the processes of the development of social and psychological anomie as a threat to spiritual security in their works.

The conditions and possibilities for the formation of a national ideology in the context of the institutionalization of spiritual security are studied by A.P. Butenko, L.N. Kochetkova, O. Kryshtanovskaya, V.N. Kudryavtsev, V.N. Kuznetsov, N.A. Narochnitskaya, A.V. Rubtsov, R.A. Rakhimov, A.G. Khabibulin, V.N. Shilov.

In the works of L.A. Bashirova, V.M. Gubanova, A. Dvorkina, Yu.P. Zueva, G.M. Kerimova, V.V. Kravchuk, T.A. Kudrina, R.A. Lopatkina, L.M. Mitrokhin, M.I. Odintsova, A.A. Radugin, A.I. Khvylya-Olinter investigates the social, political, ideological factors of the spread of non-traditional forms of religiosity in modern society.

We would like to emphasize that in the works that have appeared in recent years, the topic of spiritual security has been studied in the philosophical, ethical and sociological aspects of A. Bartosh [1], M.Blue [2], M. Boltaboyev [3], N.V. Efremova [4], A.A. Kovalev, Kudaikin E.I. [5], Omorkulov A.O. [6], F. B. Mardonova [7], K.S. Murzahalilov [8], M. L. Tatvidze [9], R. S. Salimov [10], Sh. R. Kashaf [11], F.M. Akhmedova, A.A. Kornilov [12], R. Anstey [13], Iu.V. Verminenko., N.V. Ershov [14], D. B. Mamayusupova, M. R. Gofurov [15], E.Sharipova,Zh. Kedeybaeva, K.Kurbanbaev [16].

The conditions of existence and development have become fundamentally different for our country, the threats have become different too, and, accordingly, the tasks for their timely identification, prevention and parrying are changing as well. The tasks of providing their country with the conditions of safe existence and development on a planetary scale, taken in interconnection and interdependence with the internal situation in the state, with the problems and opportunities arising in it, the imperatives and resources for their solution, and form the fundamental real state task, the continuous solution of which by the state and express, directly, in everyday life (including political) the concept of national security.

\section{Methods of research}

The methodological and theoretical basis of the article is the works, views, ideas and positions of scientists of domestic and foreign representatives of philosophy on the problems of spiritual security. In a conceptual consideration of the research, the authors were guided by such general principles of scientific research as historicism, system, formal-logical, abstraction, analogy, etc. The following approaches as system-integral, cultural-civilizational are widely used, taking into account the civilizational features of the Kyrgyz traditional culture.

The theoretical significance of the study lies in the further expansion and deepening of socio-philosophical knowledge about threats to spiritual security and its problems. The materials and results obtained in the course of the study, summarized in a social-andphilosophical concept, can be used to analyze the problems of spiritual security in Kyrgyzstan. Ensuring spiritual security is a priority, as it expresses the moral spirit of the nation, its ability to set and solve historical problems" Salimov, R.S. [17].

Understanding the conditions of personal security existed even in ancient society. One can find many different thoughts about the security problems of individuals, society and the state in the teachings of Pythagoras, Aristotle, Plato. However, the teachings of these ancient thinkers did not offer specific means to achieve the safety of both the individual and society as a whole. In their slave-owning society, there was a rather specific idea of the equality of 
people and the union of equals, which, in their opinion, is possible only if there is a state that protects everyone and provides everyone with the same security conditions.

In the XIIIth - XVIIIth centuries states (i.e. feudal sovereigns and late absolutist monarchies) recognize the importance of security conditions for their countries and the people living in them. There were being created many government security agencies in Europe. At this stage, arise the views and theoretical ideas about the role of special public services in the person of the police, gendarmerie, etc., the main task of which is to justify a set of measures to ensure the safety of citizens, society as a whole and the state.

In the XVth century Nicolo Machiavelli presented the state as an independent institution, separated from the church. In the XVI century English thinker Thomas More in the famous work "Utopia Island" presented a model of an ideal state designed to serve the whole society.

\section{Discussion}

Kashaf Sh.R. defines national security as "a state of protection of the vital interests of the individual, society and the state in all spheres of their life from internal and external dangers and threats, characterized by such a situation of the country, which ensures its integrity and internal stability, sovereign ... development, opportunity to act as an independent and fullfledged subject of international relations" [18]. The second definition we are interested in is presented on which states: "National security is the ability of a nation to satisfy the needs necessary for its self-preservation, self-reproduction and self-improvement with minimal risk of damage to the basic values of its current state" [18].

While Kyrgyzstan was part of the USSR, national security was understood as protecting the country from attacks from outside, attempted assassination of the state and social system, which, however, was more in line with the interests of Russia and the Russian people, who, in defending its own interests, assumed the responsibility and duty to protect the territories of all other republics of the Soviet Union. After the collapse of the USSR and independence of Kyrgyzstan, in addition to new historical prospects, the Kyrgyz Republic and the Kyrgyz people also faced new challenges and threats associated with the risk of economic dependence, bankruptcy and loss of nationality. The following factors as political, economic, demographic, environmental, technological and other factors began to be taken into account. As a result, there is a tendency to include in the concept of national security almost all the issues of life and activity of modern society. Kyrgyzstan, with its poorly developed economy and relatively few Kyrgyz people, faced many dangers, which, taken in their entirety, began to pose a serious threat to the existence of the nation as a specific cultural, mental and linguistic unit. The threat to the existence of a few nations arises as a result of the action of many simultaneously acting factors. However, not all of them pose the same danger, forming a certain hierarchy of hazards. Therefore, even when it comes to national security, a distinction between threats in general and threats that are already being realized is required. The threats that are already being realized should be attributed only to those that, in the real foreseeable time, can lead to elimination from the historical scene or to a significant weakening of a nation precisely as a nation that is a carrier of unique cultural, mental, linguistic and, in general.

The modern world is characterized by an extremely high, unprecedented pace of socioeconomic processes, in which the vast majority of modern states and peoples, including the Kyrgyz one, are already involved in one way or another.

Today, there are about 400 languages that are classified as endangered by specialists. Most of these languages leave the historical scene with their last native speakers. In this case, a quantitative factor is triggered, expressed in a simple and obvious formula: the fewer people speak one language or another, the greater the likelihood of its disappearance. The converse 
proposition is also true, i.e. the more people know a particular language, the greater the likelihood of a long and prosperous life. The Kyrgyz people are relatively small and for this reason, unfortunately, the Kyrgyz language can eventually become one of the endangered .

Thanks to the fact that through language a specific form of transmission of social experience, cultural norms and traditions is carried out, the succession of different generations and historical epochs is realized, the loss of one's language by one or another community in practice can lead to the loss of certain elements of social experience, cultural norms and traditions of this community and interrupting the continuity of various generations and historical epochs. Just for this reason the vast majority of ethnic groups are very sensitive to the loss of their own language, which in many respects is the spiritual death of the people. With the loss of a language and the acquisition of a new one, occurs a cardinal change in consciousness that can exist only in a certain semantic space, which in its turn can be built and organized only with the help of a language.

The real possibility of the loss of one's own language by the people is one of the most serious threats to its spiritual security, since with its loss it essentially ceases to be itself.

The next threat to Kyrgyzstan's spiritual security is Islamic radicalism. Islamic radicalism, like any religious radicalism, like any extreme socio-political form of worldview and practice, is usually attributed to the phenomena of a negative order.

It should be borne in mind that the growth of religious fundamentalism is a reaction to the acceleration of modernization and globalization processes and poses a significant threat to the spiritual security of Kyrgyzstan, contributing to ideological and psychological destabilization, the development of fanaticism and intolerance of other faiths, and the intensification of trends ethnic and confessional separatism. By stimulating religious and political extremism, fundamentalism of all denominations is also a source of numerous political threats and risks. The main danger associated with religious fundamentalism lies in its inherent tendency to oppose religious authority and statehood, believers of this denomination and Gentiles, as well as atheists, which is a factor of disintegration and fragmentation of society, weakening of the spiritual unity of the people.

The economic factor, or rather, the relatively low standard of living of the majority of the population in Kyrgyzstan, is undoubtedly a fertile ground for planting the ideology of Islamic radicalism in the minds of the Kyrgyz and other peoples of Kyrgyzstan professing Islam [19].

One of the main reasons for the spread of the ideology of Islamic radicalism in Kyrgyzstan is the external factor, the imperial imperative, or, in other words, the will to power, to expand its own influence in the system of international and interstate relations, is characteristic not only of technically developed states, but being universal, as we found out earlier, by a human property, is inherent in the Muslim world.

It should be noted that it is a mistake to consider the Muslim world as a monolithic, devoid of internal contradictions, conflict-free within itself. However, it is thanks to this circumstance that extremist tendencies, radicalism in the Islamic world as a whole, the only essential feature of which is the commitment of those professing Islam to traditional values, only intensify. Muslims widely use terrorist methods in interfaith struggle. Religious extremism or radicalism is the ideology and practice of certain movements, groups, individuals in denominations and religious organizations. It is characterized by a commitment to extreme interpretations of creed and methods of action for the implementation of goals, the spread of their views and influence. To a large extent, it is the reaction of the most fanatical adherents of religion to the process of secularization, accompanied by a weakening of the influence of religion on various aspects of public life, the adaptation of religious institutions to the changes taking place in society, and the modernization of dogma and worship. In the proper confessional environment, it can be both intra-confessional and inter-confessional. 
Adherents of religious extremism oppose the leadership of religious associations, taking a loyal position in relation to the state and accepting the changes taking place in society, against co-religionists who do not share their extreme views, as well as against other faiths and religious movements, seeing them a threat to one's identity and an obstacle to the spread of one's faith. In this regard, religious extremism often merges with clericalism and religious fundamentalism, taking the latter as its ideological platform. Characteristic features of religious extremism: extreme intolerance of dissent, all disbelievers and especially nonbelievers, the preaching of their exclusivity and superiority over others, xenophobia.

Religious extremism is manifested not only in the religious community. It is often directed against the secular state, the existing social system, the laws and norms in it, in particular, those that regulate state-confessional relations, focusing on theocratic government in the most extreme forms.

Religious extremism has manifestations in the sphere of politics, culture and in interethnic relations. In these cases, religious extremism acts as a religious motivation or religious ideological design of political, nationalist extremism, etc. Slogans, appeals, and ideological actions of extremist religious organizations are addressed, as a rule, not to reason, but to people's feelings and prejudices, designed for uncritical, emotional perception, blind commitment to customs and traditions, and the effect of the crowd. And actions, sometimes extremely cruel, are aimed at spreading fear, suppressing the opponent psychologically, and causing shock in society.

Religious slogans are often used as a cover for the political goals of fundamentalists. Therefore, we can say that fundamentalism is more a political than a religious movement, since its representatives do not come up with the ideas of reforming religion itself as a system of dogmas and rituals. They demand a change the place and role of religion in the life of society, rejecting the prevailing ideology, political practice of the existing regime and state structure as not conforming to the norms of the Muslim religion,a note from Akhmedova F.M., Kornilov A.A. [20].

Religious extremism, as well as other forms of extremism in society, gives rise to socioeconomic crises and their consequences, such as unemployment and a sharp drop in people's living standards, socio-political strains and upheavals that create a gap between the government and large groups of the population, historical insults and religious strife, the desire of social, political and ethnocratic elites and their leaders to use the religious factor to achieve their corporate goals and satisfy personal political ambitions.

Another significant threat to the spiritual security of Kyrgyzstan is represented by conflicts that arise on the basis of interethnic relations and the danger of which substantially increases precisely in connection with the Islamic factor.

Among the properties inherent in people of an ethnic association and serving as the reason for the demarcation, the most important are the group features of their activity, outside of which human being is impossible. An imbalance in the sphere of activity with limited vital natural resources took place and served as one of the most important causes of the KyrgyzUzbek conflict in 1990. The equilibrium is destroyed if any vital resources are exhausted or as a result of a certain overabundance of the population. In such cases, one of the ethnic groups or several groups, in fact, is forced to provoke a conflict. At the same time, ethnocentric ideas and moods are widely used. Ethnic egoism in these cases reaches its peak. This has been observed in two interethnic conflicts.

In addition to the imbalance in the sphere of activity, one of the main causes of both conflicts between Kyrgyz and Uzbeks, if we consider these reasons in close connection and interdependence, there were and remain certain civilizational similarities and differences. Both Kyrgyz and Uzbeks belong to communities in which traditional elements are still present to a significant extent. They are not completely traditional, but traditionalism still 
continues to dominate their trait. Traditional societies are predisposed to a state of persistent stagnation, which, with its high reproductive abilities and low production capabilities, is fraught with crises, including systemic ones. Crises, in turn, create favorable conditions for social conflicts, in the case of living different ethnic groups in the same territory, crises often lead to ethnic confrontation, interethnic conflicts.

In both interethnic conflicts between Kyrgyz and Uzbeks, which took place in 1990 and 2010, there was a confrontation between two traditional societies and, accordingly, cultures closed on themselves and to one degree or another rejecting each other, not recognizing the right to a dominant role for another culture.

A significant danger to the spiritual security of the Kyrgyz people, as well as to the vast majority of the peoples of the planet, is the modern so-called mass culture, which, in fact, is a form of expansion of the industrial culture of the West.

As it is indicated in one of the philosophical dictionaries of the post-Soviet period, mass culture is "a term used in modern cultural studies to refer to a specific kind of spiritual production, oriented to the "average" consumer and suggesting the possibility of wide replication of the original product", to write Anstey Peter and Alberto Vanzo [21].

Mass culture operates, as a rule, with basic archetypal ideas and feelings (desire for love, fear of the unknown, desire for success, hope for a miracle, etc.), by creating products based on them that are designed for an immediate emotional reaction of the consumer", to write Verminenko Iu.V., Ershov N.V. [22].

In fact, mass culture is the kind and form of culture that A. Pechcei apparently had in mind when he wrote that "the protection and preservation of the cultural characteristics of peoples and nations are rightly declared, especially in recent years, to be the key moment of human progress and self-expression. ... At the same time, people are beginning increasingly afraid of the fact that in the future all cultures may turn out to be on one face - and the face, as today's experience shows, is not too attractive - and that the movement towards depersonalizing homogeneity is already taking place" and at the same time "the further development of technological civilization, economic growth, increasing mobility of people ... the expansion of the media - all this promises in the future the fulfillment of the gloomy prophecies of the final and ruthless disappearance from the face of the earth of the lion's share of what remains of the evidence of faith, love, emotions, pride, feelings of beauty and desire for the good of past generations ", to write Mamayusupova, D. B.[23].

Mass culture is an inevitable product of the development of mankind, a direct consequence of the high level of scientific and technical achievements that allow to create a reliable, highly developed material base. On the other hand, it is that into which ethnic culture is necessarily transformed when society creates the corresponding material prerequisites. Mass culture is ripening in the bowels of ethnic culture, but over time it creates the conditions under which the ethnic culture comes to negation, and for relatively small nations to their complete negation.

In connection with the separation of mass culture into a separate type of threat to the spiritual security of the Kyrgyz people, one very important clarification is necessary. Bearing in mind the above definitions of culture, which, according to these definitions, includes language and religion, among other things - in short, everything, including spirituality itself, it makes no sense to consider it as a separate type of threat. But in this case we are talking about mass culture, and not culture in general.

Thereby, ensuring national security is primarily associated with the preservation and development of national self-awareness, reflecting the traditions of the life organization of society, its culture and history. In fact, the degradation, and then the disappearance of national (or ethnic) self-awareness means the spiritual death of the people - the carrier of this selfawareness. Therefore, everything that threatens the destruction of national self- 
consciousness, carries the danger of its dissolution in the self-consciousness of other peoples, it is a threat to the spiritual security of the people.

As a result of the information revolution that took place in the second half of the XXth century, the process of interaction between different peoples intensified significantly by gaining unprecedented dynamics, and as a result, the space of social life became denser and more mixed, becoming more homogeneous. The homogeneity of the space of social being implies the functioning of a limited number of languages in this space, which in fact means the inevitable disappearance of the vast majority of the existing ones - as the least popular. Languages, like entire nations, disappeared almost the entire history of mankind, but at the same time new languages and peoples are formed. However, modern reality in this regard is characterized by the fact that languages, due to the above mentioned reasons, began to disappear with increased intensity. In fact, the real threat of the disappearance of the Kyrgyz language is already recognized at the official level.

Thanks to the fact that through language a specific form of transmission of social experience, cultural norms and traditions is carried out, the succession of different generations and historical epochs is realized, the loss of one's language by one or another community in practice can lead to the loss of certain elements of social experience, cultural norms and traditions of this community and interrupting the continuity of various generations and historical epochs. It is for this reason that the real possibility of the loss of one's own language by the people is one of the most serious threats to its spiritual security, since with its loss it essentially ceases to be itself.

The expansion of religious fundamentalism is a reaction to the acceleration of modernization and globalization processes and it constitutes a significant threat to the spiritual security of Kyrgyzstan by contributing to the ideological and psychological destabilization, the development of fanaticism and intolerance of other confessions, and the intensification of ethnic and religious separatism tendencies. Fundamentalism of all confessions is also a source of numerous political threats and risks by stimulating religious and political extremism. The main danger associated with religious fundamentalism lies in its inherent tendency to oppose religious authority and statehood, believers of this denomination and Gentiles, as well as atheists, which is a factor of disintegration and fragmentation of society, weakening of the spiritual unity of the people.

Islamic radicalism, striving to establish the absolute dominance of religion in the life of society and the state, sees in politics only a means to achieve its goal, which is not achievable without and outside politics. A significant and favorable precondition for Kyrgyzstan for any kind of radicalism, including religious, is the fact that the political struggle in the country is closely linked to the struggle for power between regional elites, and in a difficult ethnic situation, between individual ethnic formations, which are also focused on clan and regional interests. The persistence of the phenomenon of tribalism and regionalism is explained by the entire previous history and culture of the peoples that make up the population of the region.

The acquisition of sovereignty, the involvement of Kyrgyzstan as an independent subject of international law in all kinds of processes led to the fact that it became the object of attention of many states, including Muslim ones. Islamic radicalism is to a large extent an "imported product" of the Muslim world, which is not characteristic of the mass religious Kyrgyz consciousness, as well as the consciousness in general, of radicalism. Since gaining political sovereignty, Kyrgyzstan has been involved in global geopolitical processes, in which a number of Muslim states pursue their interests, using for this and religious instruments and means of influence, including of a radical nature.

Kyrgyzstan, like all other states of the region, will continue to experience the influence of the Muslim world, which is likely to only increase over time. It would be wrong to see this 
as something exclusively negative, but orthodox, extreme Islam, using for its narrowly political goals and establishment in the republic and the region socio-economic and political instability, unemployment, mass impoverishment and impoverishment of the population, the removal of the state from solving many social problems, lack of personal protection, the dominance of the clan system and other problems, in fact, does not carry anything really positive and requires a separation from positive, moderate Islam, which does not only meet the national interests of our state, but also most closely corresponds to the Kyrgyz religious mentality and consciousness.

Value-based conflicts are particularly acute and lasting. For the Central Asian states, including Kyrgyzstan, located on the borders of the Muslim world, the conflict of values will only intensify over time. The Muslim world is heterogeneous and contradictory; it is not free from internal strife and conflicts of interest. However, in any case, in those points and territories that can, in principle, be recognized as the spiritual centers of the Muslim world, Islam is not only conservative, but also quite militantly and decisively opposed to religious and value systems that pose a definite threat to it. And this means that the states and peoples, one way or another falling under its direct and sufficiently strong influence, will transform towards Islamization by all available means and not least by radical means and methods.

The specificity of the perception of innovative elements of culture in the traditional Kyrgyz environment was significantly influenced by the long-term parallel impact of the East and West. The nomadic civilization of the Kyrgyz combined the features of both the East and the West, as a result of which collectivist and individualist, etatist and liberal principles are combined in the Kyrgyz traditional society, which greatly simplifies at the mental level, and it is essentially the main thing, any kind of cultural transformation of Kyrgyz society, including towards the acceptance of mass culture.

From the time when the Kyrgyz territories were joined to the Russian Empire, it began the most significant and rapid transformations of traditional Kyrgyz culture, which for the first time in its entire existence began to move towards mass culture due to the imposition of elements of industrial culture on the traditional cultural soil. In the Soviet times, irreversible cultural changes took place, mainly associated with the elimination of nomadic life forms and the urbanization of the republic's population. Popular culture did not become dominant among the Kyrgyz, but during this period it took deep roots into the cultural soil of the Kyrgyz people.

In a situation when serious threats to national and spiritual security arise, the people are faced with the task of preserving themselves as a certain historical and cultural community, as a nation, their state, without which they cannot have a single organization for their entire society that ensures their unity understanding of the world, the unity of the decisive will and the unity of practical actions, their historically developed state system, the existing constitutional system and the bodies acting in accordance with it.

Each state and people, in accordance with its material and spiritual power and, in accordance with the level of its material and spiritual security, there is its own set and hierarchy of threats and their causes. In conformity with this hierarchy, there must also be a hierarchy of measures that would allow effectively repelling these threats if they begin to be realized.

Socio-philosophical analysis of the spiritual sphere as a factor of national security focuses on the consideration of universal meanings, essential features and characteristics, the depth of the actualized phenomena of social life. The study of social evolution, the logic of social processes creates an opportunity to identify changes in the system of historical, spiritual, cultural and moral values and, accordingly, the dynamics of social development in situations of risks, challenges and threats. 
The conceptual status of social philosophy makes it possible to structurally represent national security in the solidity of its numerous substructures and elements. Resistance to threats to national security, the forces of ensuring it (first of all state security and public security), in cooperation with the institutions of civil society, provide with the preservation of the socio-historical, cultural and spiritual heritage.

On this basis, the national priorities for the development of the spiritual sphere are to preserve and strengthen the moral foundations of society, historical traditions, cultural and scientific potential of the country.

The preservation of the system of basic values opens opportunities for the progressive development of the individual, society and the state. In this case, spiritual security supposes the securing of conditions for stable development and allows the state to solve urgent problems of economic, social and political development.

\section{References}

1. A. Bartosh, Threats and Challenges to CSTO (NVO, 2015) https://doi.org/10.1080/1060586X.2016.1251023

2. M. Blue, Right Wing Watch 19 (2015) doi/10.1080/20566093.2016.1085243

3. M. Boltaboyev, ISJ Theoretical \& Applied Science 06(86), 668-671 (2020) Doi: https://dx.doi.org/10.15863/TAS.2020.06.86.123

4. N.V. Efremova, Islam in the modern world 16(2), 221-240 (2020) https://doi.org/10.22311/2074-1529-2020-16-2-221-240

5. A.A. Kovalev, E.I. Kudaikin, The correlation between national security and the strategy of state development of Russia (2017) https://doi.org/10.22394/1726-1139-2017-4-3946

6. K.A. Kurbanbayev, A.O. Omorkulov, ISJ Theoretical \& Applied Science 02(58), 20-23 (2018) Doi: https://dx.doi.org/10.15863/TAS.2018.02.58.6

7. F.B. Mardonova, ISJ Theoretical \& Applied Science 06(86), 748-753 (2020) Doi: https://dx.doi.org/10.15863/TAS.2020.06.86.140

8. K.S. Murzahalilov, Islam in the modern world 15(2), 167-180 (2019) https://doi.org/10.22311/2074-1529-2019-15-2-167-180

9. M.L. Tatvidze, I.G. Bochoidze, E.A. Gamkrelidze, ISJ Theoretical \& Applied Science 05(73), 371-374 (2019) Doi: https://dx.doi.org/10.15863/TAS.2019.05.73.54

10. R.S. Salimov, ISJ Theoretical \& Applied Science 06(86), 181-186 (2020) Doi: https://dx.doi.org/10.15863/TAS.2020.06.86.36

11. Sh.R. Kashaf, Islam in the modern world 11(4), 47-62 (2015) https://doi.org/10.20536/2074-1529-2015-11-4-47-62

12. F.M. Akhmedova, A.A. Kornilov, Islam in the modern world 15(1), 185-197 (2019) https://doi.org/10.22311/2074-1529-2019-15-1-185-197

13. P. Anstey, A. Vanzo, Companion to Experimental Philosophy (Blackwell, Malden, MA, 2016) https://philpapers.org/archive/ANSEME.pdf

14. Iu.V. Verminenko, N.V. Ershov, Cultural security of society and the state and its main threats (2017) DOI: 10.22394/1726-1139-2017-12-111-119

15. D.B. Mamayusupova, M.R. Gofurov, ISJ Theoretical \& Applied Science 06(86), 253-2, (2020) Doi: https://dx.doi.org/10.15863/TAS.2020.06.86.50 
16. E. Sharipova, Zh. Kedeybaeva, K. Kurbanbaev, Bulletin of Science and Practice 6(2), 362-368 (2020) https://doi.org/10.33619/2414-2948/51/46 